\title{
Mechanism and effects of cyanobacterial hepatotoxin action on human organism
}

\begin{abstract}
Eutrophication of waters and climate warming have created in the last decades favourable conditions for cyanobacteria colonization. The presence of cyanobacteria toxins in heavily polluted lake waters and fish ponds has become a current problem. These toxins belong to cyanobacteria secondary metabolites and are active in various fields of harmfulness to animals and humans. This group includes neurotoxins, dermatotoxins and hepatotoxins having a destructive influence on liver's cells. The group of hepatotoxins comprises microcystins and nodularin. The symptoms of hepatotoxin poisoning include stomach, intestine and liver disorders, intra-liver bleeding and physiological insufficiency of this organ.

These compounds can induce apoptosis of liver cells and tumor promoters. From the above facts, it follows that hepatotoxins can pose a very serious health problem on a global scale. This work presents the characteristic of cyanobacterial hepatotoxins, their chemical structure, properties, and mechanism of their action on human organism. The harmful influence caused by consuming products used in diet supplements, which contain microcystins was also pointed out.
\end{abstract}

Keywords: cyanobacteria, cyanobacterial hepatotoxins, toxic action mechanism.

DOI: $10.2478 /$ pjph-2014-0035

\section{INTRODUCTION}

Water blooming connected with mass appearance of cyanobacteria in water bodies is more and more often a consequence of eutrophication of inland and seawaters. Cyanobacteria belong to the oldest evolutionary organisms, which are characterized by enormous adaptation abilities. They inhabit all water bodies - saline and fresh, flowing and still waters. They are also present in plankton, at the bottom of water bodies or growing on water plants and objects immersed in water $[1,2]$.

Cyanobacteria appearing on a massive scale in a water body concentrate mainly on its surface, which results in blue-green color of the water. This phenomenon is caused by mass multiplication and simultaneous dying of cyanobacteria cells and other phytoplankton organisms, the consequence of which is appearance of a blue-green film on the water surface, which most often consists of Microcystis sp., Anabaena sp., Oscillatoria sp., Aphanizomenon flosaquae and Trichodesmium sp. [2]. The appearance of the above mentioned cyanobacteria species takes place most often in the period of summertime, in raised temperatures, small participation of wind and limited availability of oxygen. They constitute a problem of recreational and esthetic nature, but first of all, their presence in water bodies that are sources of drinking water is a problem of health nature both for animals and for humans. Within one cyanobacteria species there can occur toxic as well as non-toxic strains. The most toxic strains include the species from Microcystis, Anabaena, Planktothrix, Aphanizomenon, Nodularia $i$ Cylindrospermopsis genera $[3,4]$. They produce toxic compounds that are secondary metabolites and belong to one of the most toxic substances synthesized by living organisms. The amount of a lethal dose of a toxin in the form of an intraperitoneal injection in a mouse depends on cyanobacteria genus which produces it and oscillates within the range of 9-200 $\mu \mathrm{g}$ per $\mathrm{kg}$ of body mass $\left(\mu \mathrm{g} / \mathrm{kg}^{-1}\right)$. Cyanobacteria toxicity is most frequently defined on the basis of a half-lethal dose coefficient, $\mathrm{LD}_{50}$, which indicates in algae mass units per mouse body mass unit. That dose of a toxin causes mortality of the half of the tested population of animals. Some strains can produce toxins having various level of toxicity, thus, an effect of aggregation can occur. The concentration of produced toxins can be also defined in relation to total concentration of cellular proteins, algae mass unit or volume of food [5].

Toxins produced by cyanobacteria can be classified adopting various criteria of division. One of the criteria is toxicological properties. We differentiate dermatotoxins and irritants (e.g. lyngbyatoxin, aplysiatoxin, debromoaplysiotoxin), neurotoxins (anatoxins-a, homoanatoxin-a, anatoxins-a(S), saxitoxin) and hepatotoxins (microcystines, nodularis, cylindrospermopsin) $[5,6]$. Toxins can vary in chemical structure and three groups can be singled out: cyclic peptides - microcystins (heptapeptides) and nodularins (pentapeptides), alkaloids - neurotoxins and cylindrospermopsins and lipopolysaccharides [4,6]. 
For over sixty years, a research has been carried out concerning the influence of hepatotoxins produced by cyanobacteria, as well as other cyanobacteria toxins. Nowadays, 85 varieties of microcystins are known in nature and many of them are produced simultaneously by the same genus of cyanobacteria [7]. In relation to this, cyanobacteria can constitute a serious health problem on a global scale, creating new tasks for public health. Concerning the growing danger of contamination with these compounds, this study, on the basis on published data, discusses chemical structure and properties of cyanobacteria hepatotoxins, shows their negative influence on human health, explains the mechanism of action on liver cells and consequences of consuming products containing cyanobacteria hepatotoxins.

\section{CHEMICAL STRUCTURE AND MECHANISM OF ACTION OF CYANOBACTERIA HEPATOTOXIN}

Two species of cyanobacteria are listed in relation to lethal cases - M. aeruginosa and Nodularia spumigena. $M$. aeruginosa and other representatives of this genus create a family of monocyclic heptapeptid compounds called microcystins $[8,9]$. Synthesis of these compounds is energetically demanding, and therefore their connections with biological efficiency in strains producing toxins are extremely essential for understanding ecological mechanisms that are the population's reaction to global warming, eutrophication and other complex environmental powers.

In this chapter a chemical structure and mechanism of action of cyanobacteria hepatotoxins produced by representatives of three orders of cyanobacteria comprising Microcustis, Nodularia and Oscillatoria, are discussed [8].

\section{Microcystins and nodularins}

Microcystin and nodularins are the most widespread hepatotoxins in nature. They can be found in cyanobacteria blooming occurring both in fresh water basins, and in oceans. Microcystins were described on the basis of the following genera: Microcystis, Anabaena, Planktothrix, Nostoc and Anabaenopsis, whereas nodularin was found only in Nodularia [10].

Until now, the research on biological functions of cyanobacteria toxins concerned mainly microcystins. Microcystins are non-ribosomally biosynthesized with the use of multifunctional enzymatic compound called microcystin synthetase (MCS). It is codified by the mcy gene cluster, which was sequenced and characterised in microcystin species: Microcystis aeuruginosa, Planktothrix and Anabaena $s p$. [11]. Nodularin (NOD) is similar to microcystin, from the point of view of structure and function. It is biosynthesized in Nodularia spumigena [11].

Structural analysis has shown that hepatotoxins form a family consisting of at least 53 related and cyclic peptides [12]. These peptides are relatively small molecules, the molecular mass of which ranges from 800 to 1000 [Da] [13]. Majority of peptides belonging to the same family are hydrophobic and generally do not possess the ability of penetrating through vertebrates' cell membranes, and that is why they depend on ATP as a carrier. In rat's liver, an unidentified, multispecific organic anion compound (or bile acid) performs the role of a carrier of these peptides [14]. As the result, microcystin and nodularin toxicity is limited to organs, in which an organic anion carrier affects their cell membranes. A liver is such an organ, and that is why toxins affect this organ most harmfully.

The structure of heptapeptide microcystin was described for the first time in 1982, and it was based on M.aeruginosa isolate. Since then, about 60 compounds belonging to the same family of general cyclic structure (-D-Ala-L-X-DMeAsp-Y-Adda-D-Glu6-Mdha-) have been characterized [15], where $X$ and $L$ denote variables of the rest of L-aminoacids, D-MeAsp is D-erythro- $\beta$-methyl aspartic acid, and Mdha denotes N-methyl-dehydroalanine [16].

Microcystins comprise five invariant amino acids, namely, the first is d-amino acid - most frequently alanine, and also: aspartic acid, leucine or serine, the second amino acid can be alanine, arginine, glutamic acid, leucine, phenyloalanine, tyrosine or valine. In the third position, there is D-methyl aspartic acid, in the fourth: alanine, arginine, glutamic acid, leucine, methionine, phenyloalanine, tyrosine, tryptophan or valine. The fifth position is taken by 3-amino-9-methoxy2,6,8-trimethyl-10-phenyldeca-4,6-dienoic acid ADDA, and D-glutamic acid or its esters are on the sixth position, and $\mathrm{N}$-methyl-dehydroalanine is on the seventh position. One of the invariant amino acids, is the unique $\beta$-amino acid called ADDA, with toxic properties. This compound is responsible for microcystin toxicity $[16,17]$. The above-described diversity of composition has an influence on great variability of microcystin.

Microcystins are polar compounds due to the presence of free carboxylic acids in their structure and frequent occurrence of arginine; molecule's chain possesses empty places in positions 2 and 4 . Toxins are named in relation to the kind of L-amino acids connected in X and L positions. Microcystin-LR contains in these places amino acid leucine $(\mathrm{L})$ and arginine (R) $[17,18]$. Until now, over 70 kinds of microcystins different from the point of view of toxicity have been characterized [17,18]. Microcystin LR occurs most frequently in cyanobacteria, although it happens quite often, that in an individual cyanobacteria strain there is more than one genus of microcystin [19].

\section{MECHANISM OF ACTION OF CYANOBACTERIA HEPATOTOXINS}

After consuming toxic cyanobacteria by animals or humans, hepatotoxins are released due to cyanobacteria cells lysis in the digestive tract and permeate to blood in ileum. In the further stage, they are transported to hepatocytes, where they inhibit protein phosphatase activity. As the result of this process, disorders in phosphorylation and dephosphorylation in a cell take place. Microcystin and nodularin deform liver cells affecting cytoskeleton and network of protein chains, which, among others, give cells their shape [16]. The components of cytoskeleton, which are most susceptible to toxins, are polymers known as intermediate filaments and microfilaments. Sub-units are constantly being connected to or disconnected from intermediate filaments, and protein chains creating microfilaments associate 
and dissociate incessantly. Dimensions of intermediate filaments and microfilaments networks change. It is believed that after some time microcystin and nodularin cause that balance tips towards dissociation and make sub-units loss. In the first place, intermediate filaments, and in the second place microfilaments undergo changes. When the cytoskeleton shrinks, withdrawal of fingerlike projections (microvilli) takes place, through which hepatocytes interact with neighbouring cells, causing the interruption of cells contact with other hepatocytes and sinusoidal capillaries [20]. Cyanobacteria microcystin extract (MCE) causes cytoskeletal disorders and intracellular changes of glutathione in hepatocites [20]. Primary rat hepatocytes cultures exposed to cyanobacterial microcystin activity (equivalent of $125 \mu \mathrm{g} / \mathrm{ml}$ of algea cells liofilizate) demonstrated characteristic microtubul (MT) and microfilament (MF) disorders depending on the course of time. In such conditions, MCE caused aggregation of microtubuls and microfilaments and disturbed natural cytoskeleton distribution in a cell. The research shows that treating cells with MCE extract in an appropriate dose resulted in the increase of the level of intracellular glutathione (GSH). It was also found that intracellular glutathione has a significant influence on cytotoxicity evoked by MCE in rat liver cells. According to Ding and partners, the increased levels of intracellular glutathione protect cells against cytotoxicity evoked by MCE and against changes of cytoskeleton [20]. The research confirmed that hepatocites, being under influence of cyanobacteria hepatotoxins, lose their shape, disintegrate, shrink, and the liver inner structure is destroyed. The results of these processes are intra-liver bleeding and liver insufficiency, which can lead to the death of organism.

Other studies, carried out by Toivola et al., confirm that cyanobacterial toxins degrade cytoskeletal components. Microcystins and nodularins are powerful inhibitors of catalytic protein phosphatases sub-units 1 and 2a (PP1 and PP-2A) in liver cells [21]. These enzymes (protein phosphatases) act in harmony with protein kinases in the regulation of several phosphorus groups in proteins, and are important components on the course of metabolic processes.

In case of microcystin, it is postulated, that for the above effect a covalent bond of cystein-273 and cystein 266 respectively with PP1 and PP2A phosphatases, can be responsible [22-24]. Dephosphorylated protein phosphatases, PP1 and PP2A type phosphoserine-, phosphothreonine and their inhibition leads to hyperphosphorylation of cytoskeletal protein, which results in hepatocyte deformation [23,24] and damage of liver cytoskeleton.

Summing up, toxic properties of microcystins and nodularins are connected with the presence of atypical amino acid known as ADDA. This compound acts by inhibiting eukaryotic protein phosphatases, which are crucial for many regulating cellular processes such as growth, protein synthesis, glycogen metabolism and muscle contraction [16]. The function group (substituent) of ADDA is also necessary to bond toxins with protein phosphatases, which is done by covalent bonds and is highly specific [25].

\section{The influence of supplements containing blue-green algae on health}

Taking high doses of toxins produced by cyanobacteria is frequently connected with exercising water sports such as: sailing, swimming or water skiing. In these situations, accidental swallowing of water containing cyanobacteria or inhaling aerosols with cyanobacteria or their toxins may take place. It should be pointed out that toxicity of compounds absorbed by the respiratory system is often higher than taking in contaminated food. Children are among the groups with higher risk.

Because of smaller body weight and the fact that water environment is their favorite playground, they spend more time in water, and water algal bloom, its unaesthetic appearance or annoying smell do not discourage children from playing.

More and more attention is also paid to the presence of cyanobacteria toxins in consumed products, which include diet supplements produced from blue-green algae (BGA), fish or seafood [25]. Because of their concentrated form, the exposure to cyanobacterial toxins in contaminated preparations made of e.g. algae can be much higher than in case of swallowing water or contact with it during recreation activities. Products made of blue-green algae are very popular in the USA, Canada and Europe because of their supposedly good influence on physical and mental state. The presence of microcystins in food is a matter of concern due to their known strong hepatotoxic activity. Microcystin toxicity has been widely examined. After consuming, microcystins actively permeate to enterohepatic circulation from the digestive tract, and are quickly cleaned of plasma by active transport to hepatocytes $[16,20]$. Microcystins, occurring in hepatocytes, strictly bond and inhibit protein phosphatases 1 and 2A (PP1 and PP2A) leading to hyperphosphorylation of cellular proteins, which play a decisive role in maintaining the cell structure and its functioning [22-24]. Sudden exposure to the action of microcystins in big doses leads to serious damage of hepatocytes cytoskeleton causing morphological changes in hepatocytes, and in consequence, intraliver bleeding and hypovolemic shock [26].

Apart from the fact that we do not know a threshold dose of microcystins and we do not know much about possible effects of being exposed to smaller doses of microcystins, there is a serious fear that chronic exposure to smaller doses can be a serious health threat. The greatest concern is the fact that microcystins can contribute to the development of tumors [24]. It is believed that microcystins contribute to the development of tumors by PP1 and PP2A inhibition, which are integrally connected and regulate cellular cycles [23]. The mechanism of tumor creation was very well characterized on the example of toxic okadaic acid, which causes diarrheic mollusk poisoning [27]. The evidence confirming carcinogenic action of microcystins was provided by tests on animals [14-16,22,26] and epidemiological research $[16,18,25]$. Continual contact with microcystins in small doses can also lead to hepatic accumulation. The research has shown that at the time when microcystins have already penetrated the liver, the process of their expelling is very slow, and a prolonged exposure to microcystins even at very low levels can have serious consequences, and finally lead to liver cancer [26].

It has been agreed that contact with microcystins in drinking water bears a serious health risk, but exposure to the action of microcystins can be fraught with consequences in a much higher degree for the consumers of BGA products. Due to the fact that algal blooms of $M$. aeruginosa have 
a seasonal character, microcystins concentrations in surface water are sporadic, which gives a possibility of regular removal of microcystins from liver, recovery and avoiding its possible damage. However, BGA used in diet supplements are harvested during the blooming season, and next they are processed and distributed on the market all year long. Thus, if BGA are contaminated with microcystins, contact with toxin lasts uninterruptedly through the whole year. Moreover, consumption of toxins in drinking water is naturally limited, because an average consumption of water is 1.5-2 liters per day. In the case of BGA, consumption limit practically does not exist. According to the users of these supplements, their daily consumption amounts to as much as $20 \mathrm{~g}$. And thus, the potential exposure to the action of microcystin toxins through BGA supplements is much bigger than in the case of drinking water [25].

The key issue for ensuring safety of BGA supplements is carrying out sufficient tests on these products, and preparing a precise characteristic of the batch of product. Contamination of BGA supplements with microcystins can have various degrees; for ensuring safety of these products, it is necessary to carry out extensive tests and also to register precisely the produced batches. The full potential of BGA products as food supplements providing vital amino acids, antitoxins, vitamins and minerals can be obtained only when toxic risks are completely eliminated and therefore rigorous standards and tests in order to ensure safety are at present indispensable.

\section{FINAL REMARKS}

Cyanobacteria toxins - hepatotoxins constitute a serious problem of ecological and health nature. They penetrate human organism via the digestive tract, because of consuming contaminated water, diet supplements produced of blue-green algae or water organisms (crustacea, mussels, fish). Contact with cyanobacteria toxins can also take place in a dermal way during recreation while bathing in water bodies with high share of toxic cyanobacteria (during water blooming), and respiratory way by breathing water aerosols, air sprays coming from contaminated air conditioning. In spite of being microscopic organisms they can impair many vital functions of the organism, the consequence of which can pose a health and even human life threat.

The above reasons and very high carcinogenicity and toxicity of cyanobacteria are the premises for constant monitoring of water ecosystems from the point of view of cyanobacteria blooming occurrence. Safety of people doing water sports and recreating at water basins depends largely on a warning system against a possible threat of water blooming occurrence. Significant change of water color is not always enough, because problems in the form of skin changes or diarrhea can occur even at the time when cyanobacteria presence is barely visible. Even though we know quite o lot about toxic action of cyanobacteria toxins, to which, among others, belong microcystin and nodularin described in the present work, yet the research of their negative influence on human organism is to be continued. That is why the endangered ecosystems should be excluded from recreational and business use.

\section{REFERENCES:}

1. Briand JF, Jacquet S, Bernard C, Humbert JF. Health hazards for terrestrial vertebrates from toxic cyanobacteria in surfaces water ecosystems. Vet Res. 2003;34:361-7.

2. Seckbach J. Alge and cyanobacteria in extreme environments. Holandia: Springer, Dordrecht; 2007. p. 661-83.

3. Christiansen G, Molitor C, Philmus B, Kurmayer R. Nontoxic strains of cyanobacteria are the result of major gene deletion events induced by a transposable element. Mol Biol Evol. 2008;25:1695-704.

4. Mazur-Marzec H, Borowczyk-Matusiak G, Forycka K, et al. Morfological, genetic, chemical and ecophysiological characterisation of two Microcystis aeruginosa isolates from the Vistula Lagoon, southern Baltic. Oceanol. 2010;52:127-56.

5. Rogalska-Kupiec M, Bochnia T. Toksyny syntetyzowane przez sinice. Wiad Bot. 1998;42:11-9.

6. Codd G, Morrison LF, Metcalf JS. Cyanobacterial toxins: risk management for health protection. Toxicol. Appl Pharmacol. 2005;203:264-72.

7. Del Campo FF, Ouahid Y. Identyfication of microcystins from three collectoin strains of Microcystis aeruginosa. Environ Poll. 2010;158:2906-14.

8. Namikoshi M, Rinehart K L, Sakai R, et al. Structures of three new cyclic heptapeptide hepatotoxins produced by the cyanobacterium (blue-green alga) Nostoc sp. J Org Chem. 1990;55:6135-9.

9. Humpage A. Toxin types, toxicokinetics and toxicodynamics. Adv Exp Med Biol. 2008;619:383-415.

10. Chorus I, Falconer IR, Salas HJ, Bartram J. Health risks caused by freshwater cyanobacteria in recreational waters. J Toxicol Environ. Health Part B. 2000;3:323-47.

11. El-Shehawy R, Gorokhova E, Fernández-Piñas F, del Campo FF. Global warming and hepatotoxin production by cyanobacteria: What can we learn from experiments? Water Res. 2012;46:1420-9.

12. Rinehart KL, Namikoshi M, Choi BW. Structure and Biosynthesis of toxins from blue-green algae (cyanobacteria). J Appl Physiol. 1994;6:159-76.

13. Botes DP, Kruger H, Viljoen CC. Isolation and characterisation of four toxins from the blue green alga Microcystis aeruginosa. Toxicon. 1982a;20:945-54.

14. Eriksson JE, Toivola D, Meriluo'o JAO, et al. Hepatocyte deformation induced by cyanobacterial toxins reflects inhibition of protein phosphstsses. Biochem Biophys Res Commun. 1990;173:1347-53.

15. Sivonen K. Cyanobacterial toxins and toxin production. Phycol. 1996;35:12-24.

16. Carmichael WW. Health effects of toxin-producing cyanobacteria, The Cyano Habs Hum Ecol Risk. Assessement. 2001;7:1393-407.

17. Dawson RM. The toxicology of microcystins. Toxicon. 1998;36:953-62

18. Pearson LA, Neilan BA. The molecular genetics of cyanobacterial toxicity as a basis for monitoring water qality and public health risk. Cur Opin Biotech.2008;19:281-8.

19. Walker M, von Dohren H. Cyanobacterial peptides - nature's own combinatorial biosynthesis. FEMS Microbiol Rev. 2006;30:530-63.

20. Ding W-X, Shen H-M, Ong C-N. Microcystic cyanobacteria extract induces cytoskeletal disruption and intracellular glutathione alteration in hepatocytes. Environ. Health Perspec. 2000;108:605-9

21. Toivola DM, Eriksson JE, Brautigar DL. Identification of protein phosphatase $2 \mathrm{~A}$ as the primary target for microcystin-LR in rat liver homogenates. FEBS Lett. 1994;344:175-80.

22. McElhiney J, Lawton LA. Detection of the cyanobacterial hepatotoxins microcystins. Toxicol Appl Pharmacol. 2005;203:219-30

23. Honkanen RE, Dukelow M, Zwiller J, et al. Cyanobacterial nodularin is a potent inhibitor of type 1 and type $2 \mathrm{~A}$ protein phosphatases. Mol Pharmacol. 1991;40:577-83

24. McElhiney J, Lawton LA, Leifert C. Investigations into the inhibitory effects of microcystins on plant growth, and the toxicity of plant tissues following exposure. Toxicon. 2001;39:1411-20.

25. Carmitchael WW. The toksins of cyanobacteria. Sci Am. 1994;270(1):78-86.

26. Małkowski P, Pacholczyk P, Łągiewska B, et al. Rak wąrtobowokomórkowy - epidemiologia i leczenie. Przegl Epidemiol. 2006;60:731-40.

27. Falconer IR, Humpage AR. Health risk assessment of cyanobacterial (blue-green algal)toxins in drinking water. Int J Res Public Health. 2005;2:43-50.

\section{Corresponding author}

Aleksandra Zyska

Chair of Public Health, Technical University in Częstochowa

36b Armii Krajowej Str., 42-200 Częstochowa, Poland

E-mail: aleksandrazyska@gmail.com 